\title{
Dietary fiber's effect on high sensitivity C-reactive protein serum in sedentary workers
}

\author{
Livia Kurniati Saputra, ${ }^{1}$ Dian Novita Chandra, ${ }^{1}$ Ninik Mudjihartini ${ }^{2}$ \\ 1. Department of Nutrition, Faculty of Medicine, Universitas Indonesia-Dr. Cipto Mangunkusumo \\ General Hospital, Jakarta, Indonesia \\ 2. Department of Biochemistry and Molecular Biology, Faculty of Medicine, Universitas Indonesia, \\ Jakarta, Indonesia
}

Accepted 18 December 2020
Link to DOI:
10.25220/WNJ.V05.i1.0006

Journal Website: www.worldnutrijournal.org

\begin{abstract}
Low grade inflammation has been recognized of being involved in the pathogenesis of chronic disease pandemic. Individual lifestyle plays a major role in the development of low grade inflammation. Sedentary workers are at risk of low grade inflammation due to the nature of their work. Dietary habit also contributes to inflammatory status in the body. Dietary fiber intake indirectly affects the immune system. It has been hypothesized that fiber has anti-inflammatory effects, both body weight-related and body weight-unrelated This review will focus more on body weight-unrelated anti-inflammatory effect of fiber, especially through fiber's fermentation metabolites, the short chain fatty acid (SCFA). Its anti-inflammatory effect can be seen by monitoring a biomarker of inflammation in the body, the high sensitivity C-reactive protein (hSCRP). This review's objective is to cover the mechanisms and role of dietary fiber intake on serum hsCRP level as a marker of low grade inflammation on sedentary workers.
\end{abstract}

Keywords dietary fiber, high sensitivity C-reactive protein, low grade inflammation, health promotion

\section{Introduction}

Inflammation is the body's response over harmful stimuli which leads to the activation of various mechanisms on a molecular level. Depending on the severity, inflammatory reaction could be seen locally or generalized throughout the body. ${ }^{1}$ There are many causes of inflammation such as bacteria, tissue damage, or metabolic stress. ${ }^{2}$ Low grade inflammation is a type of chronic, asymptomatic inflammation. ${ }^{3}$ Low grade inflammation has been hypothesized to be a cause of insulin resistance, dyslipidemia, atherogenesis, type 2 diabetes, and hypertension. ${ }^{4}$ Risk factors for low grade

\footnotetext{
Corresponding author:

Livia Kurniati Saputra

Department of Nutrition, Faculty of Medicine, Universitas

Indonesia - Dr. Cipto Mangunkusumo General Hospital,

Jl. Salemba Raya no.6, Central Jakarta, Indonesia

Email: saputra.livia@yahoo.com
}

inflammation are imbalance diet leading to overweight and obesity, smoking, and low level of physical activity. ${ }^{3}$ These risks are commonly seen on sedentary workers in large cities. Their lifestyle is closely related to their work demand, which causes them to spend a majority of their time doing sedentary activities, having low physical activity, a smoking habit, and consumes high fat diet. ${ }^{5,6}$ All together, these factors contribute to the development of low grade inflammation which may result in declining of working productivity. ${ }^{7}$

A laboratory examination occasionally used to detect low grade inflammation is high sensitivity $\mathrm{C}$ reactive protein (hsCRP), a value of $>1 \mathrm{mg} / \mathrm{L}$ marks the presence of low grade inflammation. ${ }^{8}$ During an acute phase of inflammation, CRP is primarily synthesized by the liver and is actively involved during the course of inflammation. ${ }^{9,10}$ Chronic 
elevation of CRP is possibly related to the development of cardiometabolic diseases. ${ }^{11}$ On low grade inflammation, CRP is only slightly elevated compared to in acute inflammation. Therefore, a more advanced laboratory examination is needed to detect this lower concentration of CRP. With the innovation of hsCRP, a lower CRP concentration can be detected accurately. ${ }^{12}$

Studies have shown a probable link between dietary pattern and inflammation, especially with the consumption of dietary fiber. ${ }^{13}$ Dietary fiber plays a major role on a person's diet, however, often a modern Western diet contains low levels of dietary fiber. Low dietary fiber consumption leads to low fermentation metabolites, which has a crucial role on maintaining a healthy physiological and immune function. Low fiber diet is also one the causes of global obesity and chronic illness. ${ }^{14}$ Nevertheless, there are not many studies explaining dietary fiber's effect on biomarker of inflammation such as hsCRP, particularly on the sedentary working population. Hopefully, this study will be able to explain better of the impact of dietary fiber on serum hsCRP in sedentary workers.

\section{Materials and methods}

This is a literature study assessing the association between dietary fiber intake and serum level of hsCRP on sedentary workers with source from scientific publications dating back to 10 years ago. The data-bases were PubMed and Google Scholar. Search term used were using the explode function for subgroup terms with operators ("and,"or") for "dietary fiber", "worker", "employee", "C-reactive protein", and "dietary intake". Hand-searching were used to identify further potential eligible studies. There were no language restrictions, however only publications with full texts available were included. More than 200 publication titles and abstract were screened for their relevance to this literature review. Information extracted from each publication includes the study design, location, demographic characteristics of subjects, and dietary assessment method.

\section{Results}

After screening process, three publications were finally included. Two publications were crosssectional studies, and one was a randomized clinical trial. Two publications found association between dietary fiber and serum level of hsCRP, while one publication reported no association was observed among the two variables.

\section{Discussion}

Three studies discussing the association between dietary fibers and serum of hsCRP had inconsistent results. A cross-sectional analysis was done by Gibson et al. ${ }^{15}$ with 6898 workers of mean age $41,1 \pm 9,1$ years old, and mostly white men. Majority of subjects had moderate to high physical activity, with BMI above $25 \mathrm{~kg} / \mathrm{m}^{2}$, almost $70 \%$ of subjects were in the never smoker group. Total fiber intake was $17,3 \pm 6,0 \mathrm{~g} /$ day assessed using 7-days estimated weighed food diaries. Result showed that serum level of hsCRP is significantly lower in the highest quintile of fiber intake. A randomized controlled trial by Edrisi et al. ${ }^{16}$ was done on 105 overweight and obese workers, age 20-50 years and mean body mass index (BMI) was $29,14 \pm 3,37 \mathrm{~kg} / \mathrm{m}^{2}$ with low physical activity. Subjects were divided into three energy-restricted diet groups receiving rice bran, rice husk powder, and a control group for 12 weeks. Subjects were mostly female, with moderate physical activity level. Dietary intake, including dietary fiber and two inflammatory markers IL-6 and hsCRP were measured at baseline and endline. Mean total fiber intake ( $\mathrm{g} /$ day) were $14,96 \pm 6,89$ to $19,97 \pm 7,99$ collected using multiple 3 -day dietary record. There were no significant differences found between rice bran and rice husk groups on serum levels of IL-6 and hsCRP. Nevertheless, hsCRP reduction in both intervention group is significantly higher than in the control group.

In contrast, Khorasaniha et al. ${ }^{17}$ reported a different finding. Subjects were 257 male shift workers, age 20-60 years, mean BMI of $26,4 \pm 2,9$ to $27,3 \pm 3,2 \mathrm{~kg} / \mathrm{m} 2$, and had high physical activity. Based on their main dietary pattern assessed using semi quantitative Food Frequency Questionnaire (FFQ), subjects were divided into three groups: green, yellow, and cruciferous vegetable (VEG); liquid oils and mayonnaise, fast food and eggs (LFE); tea and coffee, refined grains and spice 
(TRS). The VEG dietary pattern was significantly associated with lower concentration of serum levels of IL-6 and TNF- $\alpha$. A significant positive association was detected between LFE dietary pattern with levels of serum IL-6 and TNF- $\alpha$. However, no significant association was found between VGE and LFE dietary pattern with serum hsCRP and between TRS dietary pattern with all of the inflammatory cytokines.

Different findings between the studies might have been attributed to several factors that possibly affect hsCRP concentration. Existing studies have used the term inflammaging for showing that aging may cause chronic low grade inflammation, resulting an increase on hsCRP level. ${ }^{18}$ Aging causes an increase of fat mass, reduced sex hormones, and increased tissue damages from oxidative stress. ${ }^{19}$ However, in the three studies compared on this review, age group of subjects are comparable. Previous studies found that serum hsCRP were higher in women compared to men. ${ }^{20-22}$ Higher value in women might be caused by estrogen fluctuation related to the menstrual cycle. ${ }^{23}$ Furthermore, women generally have higher body fat accumulation compared to men, and fat is known to be a source of proinflammatory cytokines. ${ }^{24}$ A more prominent gap is seen on menopause, where a decrease of estrogen will stimulate the production of proinflammatory markers. $^{25,26}$ In the study by Khorasaniha et al. ${ }^{17}$ subjects were exclusively male in comparison to the other two studies that included both genders.

Ethnicity is also a main contributing factor that cannot be overlooked. Asians are known to have lower level of serum hsCRP in comparison to African-American, Hispanic, and EuropeanAmerican. ${ }^{27}$ Genetic variation in the form of CRP gene polymorphism is linked to level of serum CRP in the circulation, different frequencies of this gene are seen among ethnics. ${ }^{28}$ Besides genetic, the role of ethnicity is also attributed to anthropometric measures and other risk factors, such as dietary habit and socio-economic status. ${ }^{29}$ Gibson et al. included mostly white subjects and was based in the U.K, while the study by Khorasaniha et al. ${ }^{17}$ was based in Iran. However, Edrisi et al. ${ }^{16}$ also conducted their study in Iran, so ethnicity factor could not elaborate the gap found between the two studies. As mentioned, anthropometric measure like BMI is strongly related to level of serum hsCRP. Overweight and obese subjects are at risk of having a higher hsCRP level by 1,83 and 2,63 times compared to those with normal body weight. ${ }^{30}$ An increase of white adipose tissue amount in obesity causes a rise of proinflammatory cytokines synthesis such as TNF- $\alpha$ and IL- $6,{ }^{31}$ which stimulates the production of hsCRP in liver. Edrisi et al. ${ }^{16}$ only worked with overweight and obese subjects, which had a higher mean BMI compared to the study by Khorasaniha et al. ${ }^{17}$

Additionally, medications, physical activity and smoking habit are hypothesized to affect hsCRP concentration as well. Medications like statins and non-steroidal anti-inflammatory drugs (NSAID) may lower hsCRP concentration. ${ }^{32}$ Edrisi et al. ${ }^{16}$ were the only one who excluded participants consuming lipid-lowering medication. Physical activity has an inverse relationship with hsCRP. Individuals with higher level of physical activity have lower levels of cytokines such as IL-6, IL-1, TNF- $\alpha$, toll like receptor 4 (TLR4), and hsCRP compared to individuals with low levels of physical activity. ${ }^{33}$ Subjects included by Edrisi et al. ${ }^{16}$ mostly had low physical activity, on the other hand, a majority of subjects from the study by Khorasaniha et al. ${ }^{17}$ had high levels of physical activity. Contrary to physical activity, smoking might increase hsCRP concentration. Unfortunately, out of all the studies compared in this review only Gibson et al. ${ }^{15}$ assessed smoking status. Edrisi et al. ${ }^{16}$ and Khorasaniha et al. ${ }^{17}$ excluded participants who smoked. Cigarette smoking triggers an immune response and vascular trauma which causes elevation of inflammation biomarker like hsCRP. ${ }^{34}$

Dietary pattern could also affect hsCRP levels. High intake of simple carbohydrates such as flour and sugar may cause an increase of postprandial hyperglycemia that leads to elevation of free radicals, pro-inflammatory cytokines, and hsCRP. ${ }^{35}$ Gibson et al. ${ }^{15}$ found an attenuation of the relationship between fiber intake and CRP and BMI in participant with high carbohydrate intake, defined as carbohydrate being $\geq 50 \%$ of total energy intake. High fat diet also affects the concentration of hsCRP. A high fat diet will induce migration of intestinal lipopolysaccharide (LPS) and free fatty acid to the systemic circulation, causing low grade inflammation. ${ }^{36,37}$ Despite that, only Edrisi et al. ${ }^{16}$ 
assessed total daily fat intake of subjects. Not only carbohydrate and fat intake, dietary fiber has also been reckoned to influence hsCRP concentration. Among the three studies reviewed, only two assessed total dietary fiber intake while Khorasaniha et al. ${ }^{17}$ did not. However, VEG dietary pattern are abundant in plants, ${ }^{17}$ and high fiber intake in plant model diet is related to a lower concentration of inflammatory markers. ${ }^{38}$ Although a lack of association was seen between VEG dietary pattern and serum level of hsCRP, a significant negative association was found with IL- 6 and TNF- $\alpha$ concentrations. Possibly IL- 6 and TNF- $\alpha$ is more sensitive to the effect dietary fiber compared to hsCRP, this finding is also supported by a previous study in post-menopausal women. ${ }^{27}$

A few mechanisms, as seen on figure 1 , have been stated to explain the anti-inflammatory effect of dietary fiber, especially on serum level of hsCRP. First, fermentation metabolite of fiber, also known as short chain fatty acid (SCFA), which are butyrate, acetate, and propionate is proposed to have antiinflammatory effect. ${ }^{39}$ This can be seen through its role as an agonist on three receptors inside the body, the free fatty acid 2 (FFA2), free fatty acid 3 (FFA3) dan $G$ protein-coupled receptor 109A (GPR109A). The FFA2 receptor is largely expressed on the immune cells including neutrophil, eosinophil, dendritic cells, and monocytes. The FFA3 receptor is mainly expressed on pancreas, spleen, adipose tissue and its role has been recognized on obesity and metabolic disorders. On the immune cells, FFA3 is also expressed but less when compared to FFA2. The SCFA can activate FFA2 receptor through $\beta$ arrestins-2 path, which causes NF- $\mathrm{BB}$ inhibition thereby resulting in anti-inflammatory effects. ${ }^{40}$ Activation of FFA2 also decreases proinflammatory cytokines such as IL-6 an d IL-8. ${ }^{41}$ The GPR109A receptor, also known as hydroxycarboxylic acid receptor 2 (HCA2), is found at a largely on adipocytes, and expressed on numerous immune cells. ${ }^{42}$ On adipocytes, especially white adipose tissue, GPR109A decrease lipolysis dan macrophage activation. ${ }^{43}$ Besides being an agonist to the three receptors mentioned, SCFA also works as an inhibitor to histone deacetylases (HDACs), a histone protein involved in epigenetic DNA modification. These HDACs are mainly expressed on immune cells, endothelial cells, and vascular smooth muscle. ${ }^{44}$ When HDACs are inhibited, an increase of anti-inflammatory cells production happens. Exposure of SCFA to mononuclear blood cells and neutrophil causes inactivation of $\mathrm{NF}-\kappa \mathrm{B}$ and decreases the production of the pro-inflammatory cytokine TNF- $\alpha{ }^{45}$

The second mechanism is the anti-inflammatory effect of fiber seen from polyphenols. Polyphenols are abundant in high fiber food and are studied for their antioxidant and anti-inflammatory properties. The anti-inflammatory effect of polyphenols is through their capability as a scavenger, regulating immune cells activity and modulating enzymes used in arachidonate metabolism phospholipase A2, cyclooxygenase (COX) and nitric oxide synthetase (NOS) enzyme used in arginine metabolism. On a molecular level, polyphenols inhibit enzymes on inflammation process like COX-2, lipoxygenase (LOX) and iNOS that inhibits NF- $\kappa \mathrm{B}$ and AP-1, also activation of mitogen activated protein kinase (MAPK), protein kinase-C, and nuclear factor erythroid 2-related factor. ${ }^{46}$

Obesity is one of the causes of low grade inflammation. ${ }^{7}$ Weight-related anti-inflammatory effect of dietary fiber is through adiponectin. This is the third mechanism proposed. Adiponectin plays a role on regulating insulin sensitivity, also has antiatherosclerotic and anti-inflammatory properties. ${ }^{47}$ On obese subjects, adiponectin level on the blood will decrease, and it is cause by the elevation of inflammatory mediators like TNF- $\alpha$ which inhibits genes that synthesize adiponectin. ${ }^{48}$ Adiponectin levels in the body is inversely proportional to the level of serum hsCRP. The adipose tissue contains mRNA CRP. This shows that potentially adiponectin inhibits the expression of CRP in the adipose tissue. ${ }^{49}$

\section{Conclusion}

Dietary fiber is an essential component of an individual's diet. Anti-inflammatory effect of dietary fiber can be seen on serum hsCRP. Dietary fiber may lower hsCRP serum through SCFA, polyphenols, and adiponectin. Through these various mechanisms, dietary fiber is possibly linked to the prevention of low grade inflammation and its related diseases. Currently, the number of studies covering the association between dietary fiber and 
hsCRP on sedentary workers are very limited, and have inconsistent outcomes. In the future, further studies evaluating the association between dietary fiber and serum hsCRP concentration on sedentary workers may be required.

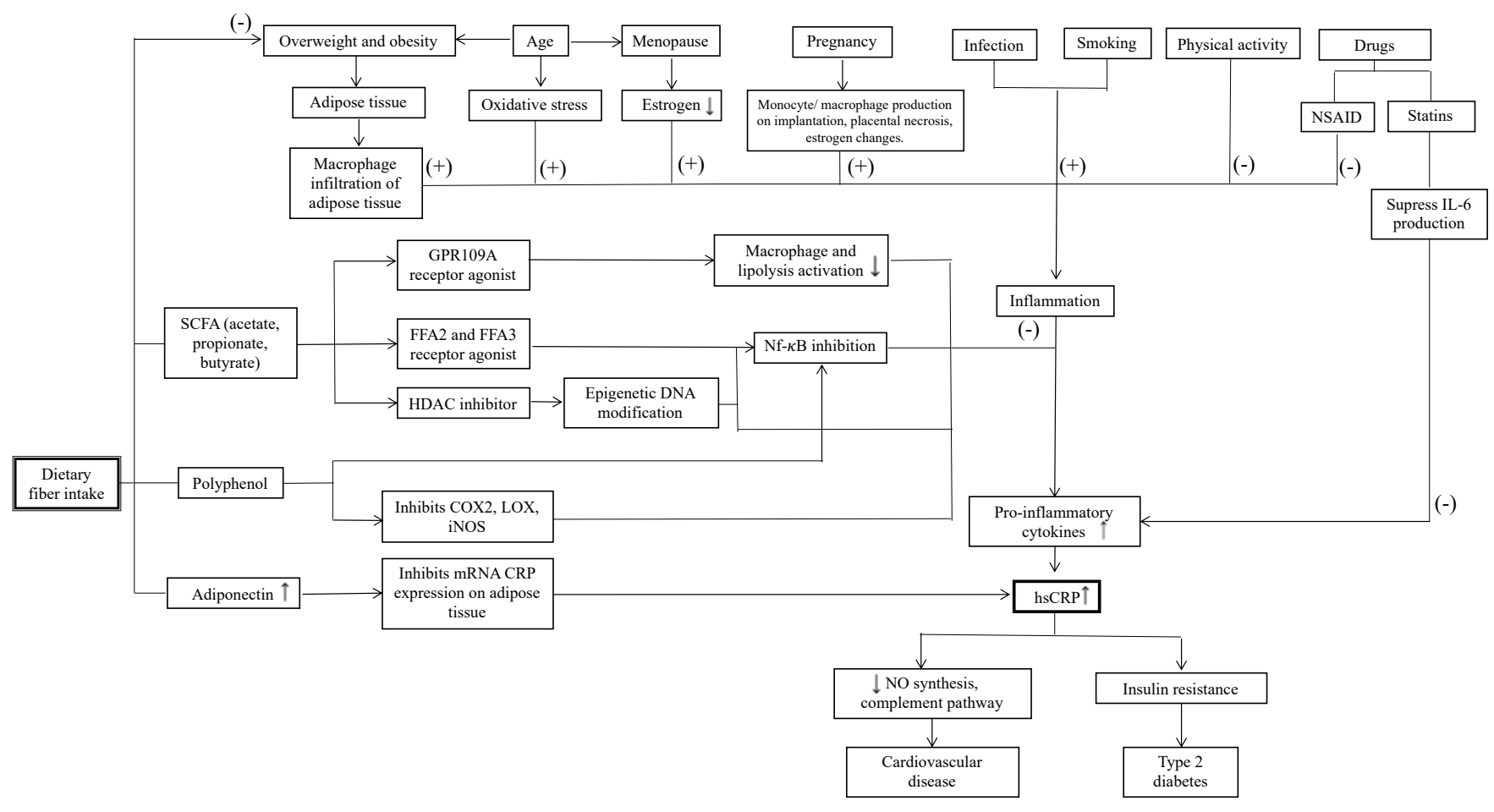

Figure 1. Effect of Dietary Fiber Intake on Serum hsCRP

COX2: cyclooxygenase 2, FFA: free fatty acid, GPR: G protein-coupled receptor, hsCRP: high sensitivity Creactive protein, HDACs: histone deacetylases, IL-6: interleukin 6, LOX: lipoxygenase, iNOS: nitric oxide synthetase, NO: nitric oxide, NF- $\kappa$ B: nuclear factor kappa B, SCFA: short chain fatty acid.

\section{Conflict of Interest}

Authors declared no conflict of interest regarding this article.

\section{Open Access}

This article is distributed under the terms of the Creative Commons Attribution 4.0 International Licence

(http://creativecommons.org/licenses/by/4.0/), which permits unrestricted use, distribution, and reproduction in any medium, provided you give appropriate credit to the original author(s) and the source, provide a link to the Creative Commons license, and indicate if changes were made. 


\section{References}

1. Fitzpatrick M, Young SP. Europe PMC Funders Group Metabolomics - A novel window into inflammatory disease. Swiss Med Wkly; 143. 2015

2. Calder PC, Ahluwalia N, Albers R, Bosco N, BourdetSicard R, Haller D, et al. A Consideration of Biomarkers to be Used for Evaluation of Inflammation in Human Nutritional Studies. Br J Nutr. 2013;109.

3. Henson J, Yates T, Edwardson CL, Khunti K, Talbot D, Gray LJ, et al. Sedentary time and markers of chronic low-grade inflammation in a high risk population. PLoS One. 2013;8(10):4-9.

4. León-Pedroza JI, González-Tapia LA, del Olmo-Gil E, Castellanos-Rodríguez D, Escobedo G, GonzálezChávez A. Low-grade systemic inflammation and the development of metabolic diseases: From the molecular evidence to the clinical practice. Cir Cir. 2015;83(6):543-51.

5. Kamso S, Purwantyastuti P, Lubis DU, Juwita R, Robbi YK, Besral B. Prevalensi dan Determinan Sindrom Metabolik pada Kelompok Eksekutif di Jakarta dan Sekitarnya. Jurnal Kesehatan Masyarakat Nasional. 2011;6(2):85.

6. Kim JY, Park YH, An EN. The relationship between lifestyles and obesity of office workers in Korea. Int J Control Autom. 2015;8(10):349-60.

7. Burton WN, Pransky G, Conti DJ, Chen CY, Edington DW. The association of medical conditions and presenteeism. J Occup Environ Med. 2004;46(6 SUPPL.):38-45.

8. Arima H, Kubo M, Yonemoto K, Doi Y, Ninomiya T, Tanizaki Y, et al. High-sensitivity c-reactive protein and coronary heart disease in a general population of Japanese: The Hisayama study. Arterioscler Thromb Vasc Biol. 2008;28(7):1385-91.

9. Sproston NR, Ashworth JJ. Role of C-reactive protein at sites of inflammation and infection. Front Immunol. 2018;9(APR):1-11.

10. Kamath DY, Xavier D, Sigamani A, Pais P. High sensitivity C-reactive protein (hsCRP) \& cardiovascular disease: An Indian perspective. Indian J Med Res. 2015;142(September):261-8.

11. Luan YY, Yao YM. The clinical significance and potential role of $\mathrm{C}$-reactive protein in chronic inflammatory and neurodegenerative diseases. Front Immunol. 2018;9(JUN):1-8.

12. Myers GL, Rifai N, Tracy RP, Roberts WL, Alexander $\mathrm{RW}$, Biasucci LM, et al. CDC/AHA Workshop on Markers of Inflammation and Cardiovascular Disease: Application to Clinical and Public Health Practice: report from the laboratory science discussion group. Circulation. 2004;110(25).

13. King DE. Dietary fiber, inflammation, and cardiovascular disease. Mol Nutr Food Res. 2005;49(6):594-600.

14. Dreher ML. Dietary Fiber in Health and Disease. Bendich A, Bales CW, editors. Vol. 6, Journal of Clinical Gastroenterology. Wimberley, TX: Humana
Press; 1984. 190 p.

15. Gibson R, Eriksen R, Chambers E, Gao H, Aresu M, Heard A, et al. Intakes and Food Sources of Dietary Fibre and Their Associations with Measures of Body Composition and Inflammation in UK Adults: CrossSectional Analysis of the Airwave Health Monitoring Study. Nutrients. 2019;11.

16. Edrisi F, Salehi M, Ahmadi A, Fararoei M, Rusta F, Mahmoodianfard S. Effects of supplementation with rice husk powder and rice bran on inflammatory factors in overweight and obese adults following an energyrestricted diet: a randomized controlled trial. Eur J Nutr. 2018;57(2):833-43.

17. Khorasaniha R, Siassi F, Khajehnasiri F, Qorbani M, Sotoudeh G. Dietary patterns in relation to inflammation in shift workers. BMJ Mil Heal. 2020;166(4):221-6.

18. Michaud M, Balardy L, Moulis G, Gaudin C, Peyrot C, Vellas B, et al. Proinflammatory cytokines, aging, and age-related diseases. J Am Med Dir Assoc. 2013;14(12):877-82.

19. Singh T, Newman AB. Inflammatory markers in population studies of aging. Ageing Res Rev. 2011;10(3):319-29.

20. Ledue TB, Rifai N. Preanalytic and analytic sources of variations in C-reactive protein measurement: Implications for cardiovascular disease risk assessment. Clin Chem. 2003;49(8):1258-71.

21. MacGregor AJ, Gallimore JR, Spector TD, Pepys MB. Genetic Effects on Baseline Values of C-Reactive Protein and Serum Amyloid A Protein: A Comparison of Monozygotic and Dizygotic Twins. Clin Chem. 2004;50(1):130-4.

22. Sutliffe JT, Wilson LD, Heer HD De, Foster RL, Jo M. C-reactive protein response to a vegan lifestyle intervention. Complement Ther Med. 2015;23(1):32-7.

23. Gursoy AY, Caglar GS, Kiseli M, Pabuccu E, Candar T, Demirtas S. CRP at early follicular phase of menstrual cycle can cause misinterpretation for cardiovascular risk assessment. Interv Med Appl Sci. 2015;7(4):143-6.

24. Oliveira A, Rodríguez-Artalejo F, Lopes C. The association of fruits, vegetables, antioxidant vitamins and fibre intake with high-sensitivity C-reactive protein: Sex and body mass index interactions. Eur $\mathrm{J}$ Clin Nutr. 2009;63(11):1345-52.

25. Milan-Mattos JC, Anibal FF, Perseguini NM, Minatel V, Rehder-Santos P, Castro CA, et al. Effects of natural aging and gender on pro-inflammatory markers. Brazilian J Med Biol Res. 2019;52(9):1-10.

26. Gameiro CM, Romão F, Castelo-Branco C. Menopause and aging: Changes in the immune system - A review. Maturitas. 2010;67(4):316-20.

27. Ma Y, Ph D, Hébert JR, Sc D, Li W, Ph D, et al. Association between dietary fiber and markers of systemic inflammation in the Women' $\mathrm{s}$ Health Initiative Observational Study. Nutrition. 2008:941-9.

28. Miller DT, Zee RYL, Danik JS, Kozlowski P, Chasman DI, Lazarus R, et al. Association of common CRP gene 
variants with CRP levels and cardiovascular events. Ann Hum Genet. 2005;69(6):623-38.

29. Kelley-Hedgepeth A, Lloyd-Jones DM, Colvin A, Matthews KA, Johnston J, Sowers MFR, et al. Ethnic differences in C-reactive protein concentrations. Clin Chem. 2008;54(6):1027-37.

30. Kawamoto R, Kusunoki T, Abe M, Kohara K, Miki T. An association between body mass index and highsensitivity C-reactive protein concentrations is influenced by age in community-dwelling persons. Ann Clin Biochem. 2013;50(5):457-64.

31. Fuentes E, Fuentes F, Vilahur G, Badimon L, Palomo I. Mechanisms of chronic state of inflammation as mediators that link obese adipose tissue and metabolic syndrome. Mediators Inflamm. 2013;2013.

32. labtestonline.org [Internet]. Washington DC: American Association for Clinical Chemistry.c2019. [cited on 20 Nov 2019] Available from: https://labtestsonline.org/tests/high-sensitivity-creactive-protein-hs-crp

33. McFarlin BK, Flynn MG, Campbell WW, Craig BA, Robinson JP, Stewart LK, et al. Physical activity status, but not age, influences inflammatory biomarkers and toll-like receptor 4. Journals Gerontol - Ser A Biol Sci Med Sci. 2006;61(4):388-93.

34. Shen J, Ordovas JM. Impact of genetic and environmental factors on hsCRP Concentrations and response to therapeutic agents. Clin Chem. 2009;55(2):256-64.

35. Esposito K, Nappo F, Marfella R, Giugliano G, Giugliano F, Ciotola M, et al. Inflammatory cytokine concentrations are acutely increased by hyperglycemia in humans: Role of oxidative stress. Circulation. 2002;106(16):2067-72.

36. Konrad D, Wueest $\mathrm{S}$. The gut-adipose-liver axis in the metabolic syndrome. Physiology. 2014;29(5):304-13.

37. Tsukumo DM, Carvalho BM, Carvalho-Filho MA, Saad MJA. Translational research into gut microbiota: New horizons on obesity treatment: Updated 2014. Arch Endocrinol Metab. 2015;59(2):154-60.

38. Smidowicz A, Regula J. Effect of Nutritional Status and Dietary Patterns on Human Serum C-Reactive Protein. Adv Nutr. 2015;(9).

39. Mcloughlin RF, Berthon BS, Jensen ME, Baines KJ,
Wood LG. inflammation: a systematic review and meta-analysis. Am J Clin Nutr. 2017;(1).

40. Li M, van Esch BCAM, Wagenaar GTM, Garssen J, Folkerts G, Henricks PAJ. Pro- and anti-inflammatory effects of short chain fatty acids on immune and endothelial cells. Eur J Pharmacol. 2018;831(April):52-9.

41. Gao H, Sun Y, Wu Y, Luan B, Wang Y, Qu B, et al. Identification of $\beta$-arrestin2 as a $G$ protein-coupled receptor-stimulated regulator of $\mathrm{NF}-\kappa \mathrm{B}$ pathways. Mol Cell. 2004;14(3):303-17.

42. Chai JT, Digby JE, Choudhury RP. GPR109A and vascular inflammation. Curr Atheroscler Rep. 2013;15(5):325.

43. Kasubuchi M, Hasegawa S, Hiramatsu T, Ichimura A, Kimura I. Dietary gut microbial metabolites, shortchain fatty acids, and host metabolic regulation. Nutrients. 2015;7(4):2839-49.

44. Zhou B, Margariti A, Zeng L, Xu Q. Role of histone deacetylases in vascular cell homeostasis and arteriosclerosis. Cardiovasc Res. 2011;90(3):413-20.

45. Vinolo MAR, Rodrigues HG, Hatanaka E, Sato FT, Sampaio SC, Curi R. Suppressive effect of short-chain fatty acids on production of proinflammatory mediators by neutrophils. J Nutr Biochem. 2011;22(9):849-55.

46. Santangelo C, Varì R, Scazzocchio B, Di Benedetto R, Filesi C, Masella R. Polyphenols, intracellular signalling and inflammation. Ann Ist Super Sanita. 2007;43(4):394-405.

47. Silva FM, De Almeida JC, Feoli AM. Effect of diet on adiponectin levels in blood. Nutr Rev. 2011;69(10):599-612.

48. Geagea AG, Mallat S, Matar CF, Zerbe R, Filfili E, Francis $\mathrm{M}$, et al. Adiponectin and Inflammation in Health and Disease: An Update. Open Med J. 2018;5(1):20-32.

49. Ouchi N, Walsh K. Adiponectin anti inflammation. Clin Chim Acta. 2009;380(1-2):24-30. 